\title{
Exploring the Social Impacts of Wildlife Conservation in Ethiopia: Past Experiences and Future Directions
}

\author{
Kabeta Legese \\ Department of Biology, Wolkite University, Ethiopia
}

\begin{abstract}
Establishing protected areas is a predominant wildlife conservation effort across Africa. Such strategy, however, has inevitable social and economic impacts to the local people. Social impacts and conservation require equal attention because it is the foundations for alliances with social groups to address common concerns. This makes social impact assessment a very crucial tool to understand the long run impacts of wildlife conservation on local people. Surprisingly, such analysis is insufficient and seemingly uncommon practices in Ethiopia. This short review examines scarcely available literatures on these matters and suggests the ways to maximize the positive and minimize the negative impacts of the sector. It is hard to understand the policies and positions of conservation sectors of Ethiopia on social impacts of conservation. Positive social impacts of conservation range from employment opportunities, improved infrastructural development to monetary gains. Negative social impacts include human displacement, lack of resource access, conflicts arising from enforcement activities, and human-wildlife conflicts. Several studies from different parts of Ethiopia have indicated the alienation of the local community and their subsequent antagonistic responses towards conservation efforts. Integrating conservation programs and local community minimizes the costs and increases the benefits of the local people. These in turn raise the social acceptance and success of the program. Wildlife conservation in Ethiopia still requires a detailed studies and practical improvements to equally address the social and biological needs of the sector.
\end{abstract}

Keywords: Costs of wildlife conservation, Ethiopia, Human displacement, Human-wildlife conflicts, Local community, Wildlife conservation

DOI: $10.7176 / \mathrm{JRDM} / 61-03$

Publication date: November $30^{\text {th }} 2019$

\section{Introduction}

Africans have experienced pre-colonial and post-colonial historical chapters of wildlife conservation (Ngoka and Lameed, 2012). Traditional wildlife resource utilization and management systems characterize the pre-colonial wildlife conservation (Roe et al. 2009). These systems have been abandoned and replaced by the idea of protected areas (PAs) during colonization, and retained even after independence (Haule et al. 2002; Kipkeu et al. 2014; Kinzig and McShane, 2015). However, the spatial strategy of setting aside PAs for wildlife conservation has unavoidable social and economic impacts (Adams and Hutton, 2007). Conservation activity should, at the very least, do no harm, and where possible should contribute to the livelihoods of local community (CBD, 2008). Concerns about social impacts of conservation are not resolved and in some respects are increasing (Springer, 2009).

Social impacts are the impacts that directly affect human wellbeing in either a positive or a negative way (Franks and Small, 2016). Positive social impacts can enable and provide incentives for sustainable management. Whereas, negative social impacts make conservation difficult and less sustainable by eroding local supports (Springer, 2009). The benefits that local communities receive from wildlife conservation include employment opportunities, improved infrastructural development to monetary gains (Larson et al. 2016), cultural and aesthetic values, improvements in health, sanitation and social services (Bajracharya et al 2006). Wildlife conservation also provides provisioning ecosystem services that improve loca.l livelihoods (Larson et al. 2016). The costs of wildlife conservation may be disproportionately borne by local people (Clements et al. 2014). Local costs of conservation includes displacement and resettlement (Coad et al. 2008), restrictions of resource uses (Beltrán and Phillips, 2000; Mariki, 2016), restrictions on access of religious and cultural purposes (Springer, 2009), conflicts arising from enforcement activities and human-wildlife conflicts (Berihun et al. 2016; Megaze et al. 2017). Crop destruction by wildlife is particularly costly, often resulting in lost income and lost time spent preventing raiding events (Larson et al. 2016). Depredation of livestock by wildlife is also experienced (Bajracharya et al. 2006).

Social impact assessment is necessary to understand the benefits and costs of wildlife conservation on the local people. This needs to consider who gains or losses, and when because the relationship between wildlife conservation and local people is dynamic and may differ among groups of people (Clements et al. 2014). The distribution of conservation benefits among local people is also equally important because quite often conservation benefits are more likely to be captured by influential people in the community (Bajracharya et al. 
2007). Social impact evaluation ensures accountability and teaches what works for both wildlife and human wellbeing (Franks and Small, 2016).

Many of the African countries have accepted the concept of PAs without considering their local context and established them without any legal agreement with the local people (Obour et al. 2016). Consequently, PAs in Africa are largely monopolized and exclusively owned and governed by the state (Kipkeu et al. 2014, Nishizaki, 2004; Teferra and Beyene, 2014). The local people have no say in the decision makings and the management of the wildlife (Nishizaki, 2004). Direct benefits that the local people gain from wildlife conservation are also negligible because financial benefits are directed to the state (Roe et al. 2009; Teferra and Beyene 2014; Kipkeu et al. 2014). However, local communities should benefit financially from neighboring wildlife resources for effective conservation because they are inherently significant stakeholders (Cheung, 2015). There is also potential imbalance in the gains and losses among those thought to be beneficial from wildlife conservation (Igoe, 2005). These problems have forced conservation agencies to reverse the top-down and state-centered conservation policies toward decentralization and local oriented participatory approaches (Nishizaki, 2004). Integration of conservation actions and local community development has gained considerable attention in recent years (Jones, 2006; Muhumuza and Balkwill, 2013).

The fundamental idea behind community based conservation is to establish economic prosperity for the participating communities through different ventures such as tourism and regulated wildlife harvesting (Noe and Kangale, 2015; Roe et al. 2009). It places local communities at the center of conservation initiatives by empowering them to manage their natural resources and derive direct benefits from them (Nishizaki, 2014). Such participation of the local people and their economic benefits then create a win-win condition in the improvement of community welfare and the conservation of wildlife concurrently (Kipkeu et al. 2014). Its growing support worldwide highlights the potential for successful integration of human livelihood goals and wildlife conservation objectives (Larson et al. 2016). Community based conservation practices were introduced into African countries in 1980s to maintain wildlife populations and to improve the socio-economic status of human communities in wildlife areas (Nishizaki, 2004; Roe et al. 2009; Kipkeu et al. 2014). However, local people in the continent are still not fully involved in wildlife management and planning (Nishizaki, 2014). Ethiopia was an independent African country from western colonialism. However, western conservation ideas equally impacted her like other colonized African countries. The country has accepted the concept of establishing PAs for very long years (Bush et al. 2013; Ketema, 2017) but the wildlife populations are still under continuous threats (Tefera, 2011). This probably because the human dimensions of PAs are not well recognized (Nishizaki, 2014; Tilahun et al. 2017).

Impacts of wildlife conservation on local community have been widely debated (Clements et al. 2014) because it involves various costs and benefits, which should all be taken into account to achieve an optimal outcome (Kipkeu et al. 2014). It is hard to understand the policies and the positions of conservation sectors of Ethiopia on the social impacts of conservation areas. However, there should be clear policies and positions regarding social impacts (Springer, 2009). This problem is probably rooted in the dominance of natural sciencetrained conservation planners in drafting and ratifying the conservation policy of the country (Adams and Hutton, 2007). Reportedly, there is a paradigm shift in wildlife conservation approach of Ethiopia with regimes changes (Ketema, 2017). Guassa-Menz community conservation area exemplifies the introduction of community based conservation systems in the country (UNDP, 2012), but conservation strategy of Ethiopia still follows protectionism and conventional methods (Nishizaki, 2005; Teferra and Beyene, 2014; Ketema, 2017). Consequently, there are numerous reports of conflicts between local communities and wildlife in and around PAs (Dakito and Bekele, 2013; Acha and Temesgen, 2015; Berihun et al. 2016). Several scholars recommended the need of understanding the local views of wildlife conservation and an improvement in local community involvement in the sector (Tefera, 2011; Megaze et al. 2017).

The new wildlife policy issued in 2007 was thought to improve community-based conservation dynamic and provide better wildlife related conflicts resolution for Ethiopia (Nishizaki, 2014), but there is no documented changes in the sector. There are also limited literatures that assess the costs wildlife conservation imposes to the local communities in the country. However, it is wrong to neglect such costs which are equally important with conservation benefits. The purpose of this paper is to review the social impacts of wildlife conservation in Ethiopia, and how they are addressed for the betterment of the practice from both conservationists and local people perspectives.

\section{Benefits of wildlife conservation}

Wildlife conservation plays vital role in conserving the species and ecosystem, and promoting resources for the benefit of local communities (Bajracharya et al. 2007). The presence of wildlife conservation habitat opens a real and potentially measurable opportunity and contribution to human welfare (Adams and Hutton, 2007). Wildlife provides important services to local people in many parts of Africa (Haule et al. 2002). Traditional uses of wildlife are prehistoric wildlife benefits that African communities have enjoyed (Ocholla et al. 2016). 


\subsection{Traditional uses of wildlife}

Local communities use wildlife for various traditional, spiritual and cultural practices (Roe et al. 2009). Sifuna (2012) classified traditional wildlife uses in African communities into socio-cultural, nutritional and medicinal benefits. There are a number of literatures on the socio-cultural benefits of wildlife in Africa (Ocholla et al. 2016; Haule et al. 2002), but yet no genuine report from Ethiopia. The uses of different body parts such as skin, horns or bones of various wildlife species for various purposes (Haule et al. 2002; Sifuna 2012), the uses of animal sounds to predict weather conditions and seasons (Ocholla et al. 2016), animals as a source of magical powers and/or strength, for worship and to appease ancestral spirits (Hakimzumwami, 2000), and the use of different animal products for various cultural ceremonies (Sifuna, 2012; Ocholla et al. 2016) are some of the socio-cultural benefits of wildlife in traditional societies.

Traditional communities obtained their food by hunting wild animals and game birds as well as collecting wild honey, wild fruits and edible roots (CBD, 2008; Mohammed, 2017). Traditional African culture seems to prefer consumptive benefits than the intrinsic benefits of wildlife (Sifuna, 2012). The reliance on wildlife resources as main food resources dated back to hunters and gatherers in the early human history. It is only that in the modern society the dependence of humans on game animals for food unlike that of their ancestors has progressively been reducing as dependence on domestic animals increased. Game meat has higher nutritional quality than the domestic meat (Larson et al. 2016). A study in Central Africa reported that local people prefer the former than the later because the former has a better taste (Hakimzumwami, 2000). Game meat can be vital for the nutritional requirements of the rural people and can also be used to change the negative attitudes and perceptions of local community that are seriously affected by depredation (Sifuna, 2012). There is a case when FAO considered game meat as one way to nourish rapidly increasing African human populations (Lindsey et al. 2015). It is believed that wildlife can play an important role in alleviating the food problem in the third world economies that are characterized by food insecurity, famine, starvation and malnutrition due low per capita income and rising levels of poverty.

Local communities from different parts of the world use different animal body parts in various forms and for treatment of various health complications (Sifuna, 2012). Many people in most rural areas of Africa rely on traditional medicine for their health care (CBD, 2008). Traditional wildlife uses are increasingly relegated and limited in Africa because of the existing government policies and laws, religious transformation and the introduction of modern way of life that undermine the existing indigenous community from the western countries (Sifuna, 2012). This is very true for Ethiopia where past governments were doing their utmost to create homogenous community both in culture and tradition.

\subsection{Contemporary uses of wildlife}

In modern day, wildlife is used more differently than earlier as public values toward wildlife have changed dramatically over the latter half of the $20^{\text {th }}$ century from consumptive to non-consumptive benefits (Mandfredo et al. 2003). Recreational values of wildlife are important sources of pleasure and enjoyment of societies, and are as important as the consumptive uses. Wildlife is used as source of employment and national income through earnings from wildlife tourism (Sifuna, 2012). Wildlife tourism is as a result of the aesthetic appeal of wildlife as tourists come for the purpose of viewing and photographing wild flora and fauna in their natural environment, and for sport hunting where permitted (Sifuna, 2012). Local communities are employed either in state and governmental agencies or in other stakeholder agencies such as hotels, tour companies and beach resorts associated with the sector to generate their livelihood options and maintain socio-cultural traditions (Bajracharya et al. 2007).

The local communities should benefit financially from neighboring wildlife resources because they are inherently significant stakeholders of wildlife conservation (Cheung, 2015). Ecotourism is responsible travel to natural areas that conserves the environment and improves the wellbeing of local people (Stem et al. 2003; Mohammed, 2017). It significantly contributes to local livelihoods and achieving conservation objectives when benefits are shared in a mutually beneficial manner (Cheung, 2015). Ethiopia have huge ecotourism potential in the form of wildlife, local culture and natural sites (Petros and Petros, 2017; Asfaw, 2014). However, several ecotourism attraction sites of Ethiopia are in danger due to the exclusion of the local communities in the decision making and management of wildlife (Teferra and Beyene, 2014). The information on ecotourism contribution to the development (Mequanint and Gebremedhin, 2015) and institutional mechanism to redistribute the benefits from conservation efforts in the country is lacking (Teferra and Beyene, 2014). Only handful of literatures documents the improvement of local community livelihoods through ecotourism. For example, Bale Mountain National Park (BMNP) has indulged local communities' off-farming activities besides cultivation and rearing of animals (Mohammed, 2017).

Wildlife is also used for scientific and educational purposes, and in modern medicines (Haule et al. 2002; Ocholla et al. 2016). Wildlife not only contributes to traditional medicine, but also modern medicine, with some of their extracts being used by pharmaceutical companies as raw material for the manufacture of drugs (Sifuna 
2012). For example, omega-3-fatty acids from fish for the treatment of arthritis and inhibitors of angiotensin converting enzyme from snake venom to treat high blood pressure (Costa-Neto, 2004).

Wildlife conservation may also address local issues and change the lifestyles of the local communities through infrastructure development such as drinking water, schools and health posts (Bajracharya et al. 2007). Conservation areas are the major tourism destinations of sub-Saharan Africa, and wildlife constitutes the key attraction of the region (Ngoka and Lameed, 2012). A study conducted by Tessema et al. (2010) in four PAs of Ethiopia reported that majority of the local communities were benefited from the conservation activities through jobs opportunities and social values. Local people can also receive a share of revenues from tourist fees and from related economic activities such as selling stuffs, food or cultural performances to tourists (Adams and Hutton, 2007; Mohammed, 2017). According to Mohammed (2017), Nechisar National Park has made Arbamich town a major tourist destination, and has improved the infrastructure of the town. This has also played a key role in advertising Gamo culture throughout the country and to the international community as well.

\section{Costs wildlife conservation imposes to local people}

The establishment of PAs goes hand-in-hand with an increase in conservation costs to communities living in and adjacent to these PAs (Mariki, 2016). This is because PAs were established on lands that were once owned by local communities. Conservation benefits do not usually strengthen the types of livelihoods that were weakened by exclusion from PAs (Igoe 2005). Wildlife conservation will inevitably have some negative impacts on some people living close to such areas (Curran et al. 2009). A recent study from Kenya has reported that PAs worsened the relevant livelihood needs and wellbeing of local communities (Mariki, 2016). Wildlife conservation should therefore consider rights of local people; otherwise generates economic and social hardships with unwanted score to them (Bajracharya et al. 2007). This in turn may lead to the migration of the local people because of lack of access to resources, escalating wildlife depredation, and leading to frequent assaults by soldiers and park staff. Others abandon cultivating their land to avoid crop damage by wildlife (Bajracharya et al. 2007; Sirima 2016). Local people claims increased livelihood risks and the loss of cattle due to inadequate pasture areas (Teferra and Beyene 2014; Sirima 2016).

The impacts of wildlife to the local community can be in terms of damage to crops, livestock predation, injuries to human beings, and losses of human lives (Haule et al. 2002; ). Several studies reported injuries to human beings and even death due to wild animal attacks (Haule et al. 2002; Acha and Temesgen 2015). It also involves the lack of access to wildlife resources for religious and cultural purposes (Springer 2009), restriction on the use of the resources (Beltrán and Phillips 2000), conflicts from enforcement activities (Springer, 2009) and displacement and resettlement (Coad et al. 2008). Since conservation judgment is based on what benefits it brings to them, their participation is possible only if conservation enhances the local economy (Bajracharya et al., 2007). There is the case when the local people attribute their poverty to wildlife (Sifuna, 2012). To know whether communities are experiencing a net loss or a net gain from wildlife conservation, we must first understand the opportunity costs of PAs before we can understand their benefits to communities (Igoe, 2005). But unnoticeable study is carried out and available on this issue in Ethiopia.

\subsection{Human displacement and resettlement}

Displacement is the greatest social impacts of wildlife conservation that has a direct impact on livelihoods (Adams and Hutton, 2007). It involves removing people from their ancestral land or excluding them from undertaking livelihood activities in their usual areas (Sirima, 2016). Restricted access to certain natural resources is recently considered as one form of involuntary displacement (Cernea, 2006). PAs were once populated and people were moved by colonial and post-colonial authorities (Coad et al. 2008). Some groups within communities are likely to have experienced the costs of evictions more than others (Igoe, 2005). Some groups within communities are also better positioned to take advantage of conservation benefits than others although they are often not the same groups who have borne most of the costs for conservation (Bajracharya et al. 2007). Paradoxically, the displacement of people from PAs has long been dependent on identity. This is well witnessed by the fact that tourists and scientists have normally been tolerated in PAs even where local resource users have been excluded (Adams and Hutton, 2007). Most rural people near the PAs attribute their poverty to wildlife because government authorities tend to alienate wildlife from the people and deny them the historical benefits they have enjoyed from wildlife through the ages (Sifuna, 2012).

The displacement of local people from PAs is one of the most controversial and contested aspects that has received a great deal of attention in recent years (West et al. 2006). It is often used to highlight the conflict between conservation and poverty reduction (Coad et al. 2008). According to these scholars, there is poor knowledge of the scale of displacement events, long-term residency and migration into PAs. There is also a lack of information on the number of people currently living within PAs. It is also difficult to predict how many people may be affected by displacement in the future. These problems are more prominent in Ethiopia, where it is very difficult to obtain an independent scientific literature on the topic partly because most studies are 
conducted by natural science scholars that favor the biological aspects of conservation. Here, wildlife conservation policy of the country has also huge role to play as it follows wildlife-first philosophy for long years (Teferra and Beyene, 2014). Thus, social science scholars are rarely seen in engaging themselves on this area and in the sector.

Most literatures suggest local people displacement for wildlife conservation was historical but accelerated in the $20^{\text {th }}$ century (Krueger 2009). Most of the displacements of the local people are from the PAs in the Africa continent. Very few studies mention compensation for displacement, through land or money; those that do tend to provide examples of inadequate or absent compensation (Coad et al. 2008). In Ethiopia, for example, Nechasar National Park has relocated more than 1000 Kore families and burnt down 463 houses belonging to Guji people by police and park authorities in 2004 and 2005 (Nishizaki, 2004). Awash National Park has also displaced Karrayu pastoral group without adequate compensation (Coad et al. 2008). Similar displacement was made from Omo National park (Adams and Hutton, 2007). Even if they were able to return after years, Semien Mountains National Park also expelled a large number of inhabitants from villages both in the vicinity and inside the park in 1978 (Beltrán and Phillips 2000). Countries may be more likely to displace people from PAs if their history has been one of strict government control. There is also some evidence of ulterior political motives for displacement (Coad et al. 2008). A repeated forceful eviction of Guji Oromos from Nechasar National Park, inadequate compensations after evictions, and low scientific documentation uncovering of such cases strongly support the ulterior political motives behind local people displacement in Ethiopia.

Most case studies on the effects of displacement on livelihoods of local people fail to provide adequate and detailed information (West et al. 2006). Even though there are recent attempt to assess the costs of displacement, only a handful has used quantitative measurement methods (Coad et al. 2008). According to these scholars, landlessness, joblessness, homelessness, marginalization, food insecurity, increased morbidity, inability of access to common property, and mortality and social disarticulation are the major livelihood impacts of displacement. West et al. (2006) predicted the remarkable increase in the level and rate of evictions if current conservation is strictly applied.

The displacement of local people from their ancestral lands without detailed studies and adequate compensations have direct consequences not only the local people but also on the conservation programs. This is because displaced people may develop negative attitudes and resentment to the wildlife conservation after their eviction (Coad et al. 2008) than cooperating. Hence, managing displacement in equitable ways contribute to the fair distribution of costs and benefits of wildlife conservation (Krueger, 2009). Impartial studies of the number of displaced people, who receive compensation, and the effects of this compensation in mitigating the costs of displacement should be in place to effectively succeed in both themes.

\subsection{Restriction of access to resources}

Local communities may be allowed to remain within or adjacent to PAs, but loss land use rights that can produce many of the same risks outlined for displaced people (Coad et al. 2008). Dispute over land-use between the local people and wildlife conservation agencies is becoming a serious problem in developing countries including Ethiopia (Nishizaki, 2004). The increase in disputes over land-use is caused by combined factors such as expansion of cropland due to rapid population growth, policy change for tenure, and mismanagement by the conservation agency (Beltrán and Phillips, 2000). The evolutionary concept of western wildlife conservation has also its own share for the failure of conventional conservation methods (Nishizaki, 2004). This has generally resulted in local communities developing negative public attitudes towards wildlife which they now perceive as a liability instead of a resource (Sifuna, 2012). The conflicts with the local people become more severe when prohibition of resource use within PAs is coupled with various forms of man-animal conflicts such as crop raiding, cattle lifting, and loss of human lives and property (Mishra et al. 2009).

Almost by definition PAs will result in resource restriction to local communities, with the level of restriction varying with the individual characteristics and management of each area (Coad et al. 2008). African traditional wildlife uses are severely threatened and seriously undermined by the modern way of life, government policies and the laws (Sifuna, 2012). Most often, local people are not allowed harvesting wildlife and wildlife products (Igoe, 2005). The most frustration case is also their alienation from wildlife and denial from the historical benefits they have enjoyed from wildlife through the ages (Nishizaki, 2004; Sifuna, 2012). It is believed that local communities should be allowed to exploit some resources from the PAs when this does not conflict with conservation interests (Haule et al. 2012).

Historically, no PAs in Ethiopia considered both the needs and the role of local people during their establishment (Beltrán and Phillips, 2000; Nishizaki, 2004). For example, in 1976 the government regarded Senkelle Swayne Hartebeest Sanctuary as the areas of no man's land and ignored the existence of the local people. Since then, local activities, such as grazing, hunting and collecting useful plants were strictly banned. If a man went into the sanctuary for grazing, his cattle were confiscated, or he was fined by the scouts who guarded the sanctuary (Nishizaki, 2004). A case study conducted in Semien Mountains National Park also indicated the 
engagement of the park management in forcing resident people to emigrate from the park by making the area as unattractive as possible through prohibiting any development activities (Beltrán and Phillips, 2000). In many local communities, especially in Ethiopia, the people have therefore no longer seen the importance of wildlife instead they consider as a threat to their existence (Nishizaki, 2004; Dakito and Bekele, 2013; Teferra and Beyene, 2014).

The communities from different PAs reflected their traditional resources access exclusion by requesting access to traditional resources like pasture, firewood, and key water points for improved relations (Tessema et al. 2010). Traditional wildlife resources use practices restriction or denial also results the cultural losses of the local communities (Krueger, 2009). The excitement of the local people by one day visit to Mago National Park also confirms the alienation of the local people access to the PAs in Ethiopia (Nishizaki, 2005). With this kind of perceptions, however, the people are unlikely to support conservation. This suggests the need to deploy traditional eco-friendly knowledge, skills and practices to justify the rights of local people and responsibility to be involved in the management of local resources (Bajracharya et al. 2007). The local claims and rights to access the land must be recognized and considered in advance in any conservation policy making processes (Nishizaki, 2004).

\subsection{Human-Wildlife conflicts}

Conflict is a relationship between two or more parties who might have incompatible goals, values, interests, or behavior (Teferra and Beyene, 2014). Human-wildlife conflict is a negative interaction between human and wildlife that happens when the action of either human or wildlife affects the other (Madden, 2004; Habib et al. 2015; Rakshya, 2016). Conflict between people and wildlife has been in existence for as long as humans have existed and wild animals and people have shared same landscapes and resources (FAO, 2009; Habib et al. 2015). However, it increased in frequency and severity recently (Madden, 2004) and became undisputable, and a difficult conservation challenge worldwide (Rakshya, 2016). It is also predicted to continue and escalate in the future (Madden, 2004). The phenomenon is more prominent in developing countries especially in the subSaharan African countries (FAO, 2009).

The popularity of conflict between wildlife and local people in Africa is because wildlife habitats are greatly transformed and reduced due to rapid human population growth and other associated anthropogenic factors (Teshome and Girmay, 2017). This increased the frequency of encounters between humans and predators inevitably leading to conflict (Chueng, 2015). The conflict escalates when local people feel that the needs or values of wildlife are given priority over their own needs, or when local institutions and people are inadequately empowered to deal with the conflict (Madden 2004). If protected area authorities fail to address the needs of the local people or to work with them to address such conflicts adequately, conflicts intensify, becoming not only conflict between humans and wildlife, but also between humans about wildlife (Madden, 2004).

On the basis of the impacts of the wild animals, human-wildlife conflicts in the sub-Saharan Africa can be viewed in three major forms. The most common form of human-wildlife conflicts in agrarian communities is human-herbivores conflicts (Dakito and Bekele, 2013). In such conflicts, wild animals are problematic to the local communities through the damage on the agricultural crops. Hippopotamus, African elephants, African buffalos, antelopes and primates are the major crop raiders in the continent (Ngene and Omondi, 2009; FAO 2009; Dakito and Bekele, 2013; Berihun et al. 2016). According to Girmay and Teshome (2017), birds are also considered as crop raiders by the farmers in eastern Tigray, North Ethiopia. Berihun et al. (2016), however, reported the shifting in the feeding behavior of monkeys and apes from herbivory into livestock depredation from Kafita Sheraro National Park in northern Ethiopia.

The second form of human-wildlife conflict is human-carnivore conflict, which occurs between livestock depredating animals and humans. Livestock depredations happen when wild carnivores kill livestock as food sources. Cheetah, wild dog, crocodile, jackal, lion, leopard, and hyena are the major livestock depredators in subSaharan Africa including Ethiopia (FAO, 2009; Berihun et al. 2016; Girmay and Teshome, 2017). The third form of human-wildlife conflict in African continent is the combination of the two (human-omnivore conflict), in which human and wildlife negatively interact both through crop raiding and livestock depredation by the same wild animal species. Baboon, rodents and the like are wild animals that belong to this category (Berihun et al. 2016; Girmay and Teshome, 2017; Dakito and Bekele, 2013).

Human population growth and expansion, habitat degradation and fragmentation, land-use transformation and increasing densities of livestock grazing in PAs are considered as major causes of man-carnivore conflicts (Teferra and Beyene, 2014; Habib et al. 2016). Gobosho et al. (2016) also reported habitat disturbances, proximity to the forest areas and the combination of these factors as the major causes of human-wildlife conflicts in southern Ethiopia. Human-wildlife conflicts pose from minor to serious problems to the local community. Major impacts of such interaction are the loss of primary food, cash crops, and livestock (Acha and Temesgen, 2015; Berihun et al. 2016; Gobosho et al. 2016). However, human injuries and death due to direct 
attack, social costs from disturbing sleeping time, and children schooling for guarding such problematic animals are another local consequence of human-wildlife conflicts in rural areas of developing countries (Adams and Hutton, 2007; Bajracharya et al. 2007; FAO, 2009). Several studies reported human attack and death by crocodiles, lions and leopards (Madden 2004; FAO 2009). Acha and Temesgen (2015) reported human attack causalities by baboons, buffalos, lions, hyenas and leopard from southern Ethiopia in and around Chebera Churchura National Park. Exposure to certain disease such as malaria during night guarding is also reported from malaria prone areas (Teshome and Girmay, 2017). Park neighbors can also be exposed to corrupt rent-seeking behavior by PA staff, particularly linked to minor infringements of park boundaries (e.g. impoundment of stock alleged to be grazing illegally), or of regulations (e.g. informal charges to avoid arrest or fines for cutting fuel wood, or collecting medicinal plants) (Adams and Hutton, 2007).

\section{Future Directions}

Several scholars argued the low level of local people involvements in wildlife conservation of Ethiopia (Beltrán and Phillips 2000, Nishizaki 2004, 2005) and the infancy of community based conservation and its incomplete cascading to all stakeholders in the country (Tefera 2011; Mulualem and Tesfahunegny 2016a). If the successes of wildlife conservation are wanted to be insured, these problems must be timely addressed and solved first. The denial of local communities from wildlife and wildlife products access has positively shaped the attitudes and perceptions of the local society toward wildlife conservation (Teferra and Beyene 2014). Benefits of local community from wildlife conservation should be increased by infrastructural developments, revenue sharing, and increased involvement in wildlife conservation decision makings and employment opportunities. Fair and equitable sharing of wildlife resources and other related profits for the local community should be installed to ensure the spirit of ownership of the resources among the local people.

Traditional taboos and belief systems of the local community on wildlife use are recently considered as another pillar of sustainable wildlife conservation throughout Africa (Jones et al. 2008; Sifuna, 2012; Ngoufo et al., 2014; Diawuo and Issifu 2015). However, there is limited published information on taboos and traditional practices that are used to regulate the behavior of local people uses of wildlife in Ethiopia. Identification and recognition of such traditional customary laws in several traditional societies of the country and integrating them with modern wildlife conservation practices are highly recommendable.

Displacement of the local people, crop damage, livestock depredation and human attacks are some of the costs to the local people living close to the wildlife (Haule et al. 2002; Coad et al. 2008; Dakito and Bekele 2013; Acha and Temesgen 2016). These factors have a prominent role in shaping the attitudes and perceptions of local community towards wildlife and conservation. If needed, these costs to the local people should be addressed, carefully evaluated and correctly answered for the successes of wildlife conservation. Some of the possible solutions to these challenges could be instilling displacement based on consent and adequate compensation, an appropriate compensation for crop and livestock damaged by wildlife (Muhumba and Backwill 2013) and devising sounding and effective management strategies to mitigate human-wildlife conflicts (Bajracharya et al. 2007). Finding the ways that generate adequate incentives for the local communities will also motivate the communities to adopt land-use practices that are compatible with wildlife conservation and management (Kipkeu et al. 2014).

Monitoring of social impacts play a directing role in changing course of action when problem arise and to demonstrate the relevance of conservation to the social agendas (Springer, 2009). Thus, such monitoring systems and studies should be a tradition in any conservation program of the country. in drafting and ratifying the conservation policy of the country has probably played significant role in relegating the social impacts of conservation. Hence, the door should be equally opened for social science trained conservation planners to have a balanced and comprehensive conservation planning policy.

\section{Conclusion}

Social impacts of wildlife conservation in Ethiopia are thinly studied, and probably neglected area of wildlife conservation. Even scarcely available social researches on conservation planning merely analyze the impacts of human on biodiversity, but not the impacts the conservation practices pose on the society. Hence, more research works is needed to clearly understand what impacts conservation interventions pose on the local community as equal to the impacts they pose on the wildlife. As far as this area is not clearly understood and appropriately addressed, the success of wildlife conservation in the country is in jeopardy. Building collaboration with the local communities and indigenous people and expanding it should also be a critical future direction of conservation sectors in the country.

\section{References}

Acha A, Temesgen, M. 2015. Approaches to human-wildlife conflict management in and around CheberaChurchura National Park, Southern Ethiopia. Asian Journal of Conservation Biology 4:136-142. 
Adams W. M, Hutton J. 2007. People, parks and poverty political ecology and biodiversity conservation. Conservation \& Society 5: 147-183.

Asfaw A. 2014. Development of community based ecotourism in Borena-Saynt National Park, north central Ethiopia: opportunities and challenges. Journal of Hospitality and Management Tourism 5: 1-12.

Bajracharya B, Furley A, Newton C. 2006. Impacts of community-based conservation on local communities in the Annapurna Conservation Area, Nepal. Biodiversity and Conservation 15: 2765-2786.

Bajracharya B Gurung H, Basnet K. 2007. Learning from community participation in conservation area management. Journal of Forest and Livelihood 6:54-66.

Beltrán J, Phillips A. 2000. Indigenous and traditional peoples and protected areas principles, guidelines and case Studies. World Commission on Protected Areas Best Practice Protected Area Guidelines Series No. 4 IUCN. Pp. 133.

Berihun A, Yirga G, Tesfay G. 2016. Human-wildlife conflict in Kafta-Sheraro National Park, northern Ethiopia. World Journal of Zoology 11: 154-159.

Bush, G, Hanley N, Moro M, Rondeau D. 2013. Measuring the local costs of conservation: a provision point mechanism for eliciting willingness to accept compensation. Land Economics, 89: 490-513.

CBD (Convention on Biological Diversity). 2008. Ninth conference of the parties to the convention on biological diversity, decision IX/18, Bonn.

Cernea M. 2006. Re-examining "Displacement": a redefinition of concepts in development and conservation policies. Social Change 36: 8-35.

Cheung, H. 2015. Ecotourism as a multidisciplinary conservation approach in Africa. Therya 6: 31-41.

Clements T, Suon S, Wilkie D, Milner-Gulland J. 2014. Impacts of protected areas on local livelihoods in Cambodia. World development 64:125-134.

Coad L, Campbell A, Miles L, Humphries K. 2008. The Costs and Benefits of Protected Areas for Local Livelihoods: a review of the current literature. Working Paper. UNEP World Conservation Monitoring Centre, Cambridge, U.K. Pp. 42.

Costa-Neto M. 2004. Animal-based medicines: biological prospection and the sustainable use of zootherapeutic resources. Annals of the Brazilian Academy of Sciences 77: 33-43.

Curran B, Sunderland T, Maisels F, Oates J, Asaha S, Balinga M, Defo L, Dunn A, Telfer P, Usongo L, von Loebenstein K, Roth P. 2009. Are central Africa's protected areas displacing hundreds of thousands of rural poor? Conservation and Society 7: 30-45.

Dakito D, Bekele A. 2013. Conservation challenge: human-herbivore conflict in Chebera Churchura National Park, Ethiopia. Pakistan Journal of Biological Sciences, 16: 1758-1764.

FAO (Food and Agriculture Organization). 2009. Human-wildlife conflict in Africa: causes, consequences and management strategies. FAO technical paper. Pp. 98.

Franks P, Small, R (2016) Understanding the social impacts of protected areas: a community perspective. IIED Research Report. IIED, London.

Girmay T, Teshome Z. 2017. Human-wildlife conflicts in and around Choffa forest, Hawzien Woreda, eastern Tigray, northern Ethiopia: implication for conservation and conflict resolution. International Journal of Science and Research, 6: 2319-7064.

Gobosho L, Hunde D, Mekonnen T. 2016. Assessment of types of damage and causes of human-wildlife conflict in Gera district, south western Ethiopia. Journal of Ecology and the Natural Environment 8: 49-54.

Habib A, Nazir I, Fazili F, Bhat A. 2015. Human-wildlife conflict-causes, consequences and mitigation measures with special reference to Kashmir. Journal of Zoology Studies 2: 26-30.

Hakimzumwami E. 2002. Community wildlife management in central Africa a regional review. Evaluating Eden series discussion paper no.10. Pp. 62.

Haule S, Johnsen H, Maganga L. 2002. Striving for sustainable wildlife management: the case of Kilombero Game Controlled Area. Tanzania Journal of Environmental Management 66: 31-42.

Igoe J. 2006. Measuring the costs and benefits of conservation to local communities. Journal of Ecological Anthropology 10: 72-77.

Jones S. 2006. A political ecology of wildlife conservation in Africa. Review of African Political Economy 33: 483-495.

Jones J, Andriamarovololona M, Hockley N. 2008. The importance of taboos and social norms to conservation in Madagascar. Conservation Biology 22: 976-986.

Ketema D. 2017. Ethiopia: Changes from "People out Approach" protected area management to participatory protected area management? Insight from Ethiopian protected areas. Journal of Environmental Science, Toxicology and Food Technology 11: 49-55.

Kinzig A, McShane T, 2015. Conservation in Africa: exploring the impact of social, economic and political drivers on conservation outcomes. Environmental Research Letters 10: 1-4.

Kipkeu L, Mwangi w, Njogu J. 2014. Incentives for enhanced community participation in wildlife conservation 
in Amboseli, Kenya. International Journal of Research in Applied Natural and Social Sciences 2: 75-86.

Krueger L. 2009. Protected areas and human displacement: improving the interface between policy and practice. Conservation and Society 11: 25-29.

Larson R, Conway L, Hernandez M, Carroll P. 2016. Human-wildlife conflict, conservation attitudes, and a potential role for citizen science in Sierra Leone, Africa. Conservation and Society 14: 205-217.

Lindsey P, Taylor A, Nyirenda V, Barnes L. 2015. Bush meat, wildlife-based economies, food security and conservation: Insights into the ecological and social impacts of the bushmeat trade in African savannahs. FAO report, pp. 58.

Madden M. 2004. Creating coexistence between humans and wildlife: global perspectives on local efforts to address human-wildlife conflict. Human Dimensions of Wildlife 9:247-257.

Megaze A, Balakrishnan M, Belay G. 2017. Human-wildlife conflict and attitude of local people towards conservation of wildlife in Chebera Churchura National Park, Ethiopia. African Zoology 52: 1-8.

Manfredo J, Teel L, Bright D. 2003. Why are public values toward wildlife changing? Human Dimensions of Wildlife 8:287-306.

Mequanint F, Gebremedhin S. 2015. Contribution of local community for ecotourism development in and around Abjiata Shalla Lakes National park with emphasis to women's role, Ethiopia. Australiasian Journal of Social Sciences 1:1-19.

Mariki SB. 2016. Social impacts of protected areas on gender in West Kilimanjaro, Tanzania. Open Journal of Social Sciences 4: 220-235.

Mishra K, Badola R, Bhardwaj K. 2009. Social issues and concerns in biodiversity conservation: experiences from wildlife protected areas in India. Tropical Ecology 50: 147-161.

Mohammed A. 2017. Review on impacts of protected area on local communities' livelihoods in Ethiopia. Journal of Resources Development and Management 39: 1-13.

Muhumuza M, Balkwill K. 2013. Factors affecting the success of conserving biodiversity in National Parks: a review of case studies from Africa. International Journal of Biodiversity 1:1-20.

Ngene M, Omondi P. 2009. The costs of living with elephants in the areas adjacent to Marsabit National Park and Reserve. Pachyderm 45: 77-87.

Ngoka C, Lameed A. 2012. Adapting a community-participatory wildlife conservation model to management of Nigerian National Parks for sustainable tourism. Transactions on Ecology and the Environment 161: $307-$ 319.

Nishizaki N. 2004. Imposed wildlife conservation: Arssi Oromo and the Senkelle Swayne's Hartebeest Sanctuary, Ethiopia. African Study Monographs 25: 61-77.

Nishizaki N. 2005. Differing local attitudes toward conservation policy: a case study of Mago National Park, Ethiopia. African Study Monographs 29: 31-40.

Nishizaki N. 2014. Neoliberal conservation in Ethiopia: an analysis of current conflicts in and around protected areas and their resolution. African Study Monographs 50: 191-205.

Noe C, Kangalawe R. 2015. Wildlife protection, community participation in conservation, and (dis) empowerment in southern Tanzania. Conservation and Society 13: 244-253.

Obour R, Asare R, Ankomah P, Larson T. 2016. Poaching and its potential to impact wildlife tourism: an assessment of poaching trends in the Mole National Park in Ghana. Athens Journal of Tourism September 3: 169-192.

Ocholla O, Mireri C, Muoria K. 2016. Application of indigenous knowledge systems in wildlife management: a case study of the Samburu pastoral community in Kenya. International Journal of Applied Science and Technology 6: 72-80.

Petros I, Petros T. 2017. Opportunities and challenges for community-based ecotourism development: a case study in Dinsho and Goba Woredas, Southeast Ethiopia. International Journal of Ecology and Ecosolution 4: 5-16.

Rakshya T. 2016. Living with wildlife: conflict or co-existence. Acta Ecologica Sinica 36: 509-514.

Roe D, Nelson F, Sandbrook C. (eds). 2009. Community management of natural resources in Africa: impacts, experiences and future directions, Natural Resource Issues No. 18, International Institute for Environment and Development, London, UK. Pp. 190

Sifuna N. 2012. The future of traditional customary uses of wildlife in modern Africa: a case study of Kenya and Botswana. Advances in Anthropology, 2: 32-38.

Sirima A. 2016. The social and economic impacts of Ruaha National Park expansion. Journal of Social Sciences 4: $1-11$.

Springer L. 2009. Addressing social impacts of conservation: lesson from experiences and future directions. Conservation and Society 7: 26-29.

Stem C, Lassoie P, Lee, R, Deshler D, Schelhas JW. 2003. Community participation in ecotourism benefits: the link to conservation practices and perspectives. Society and Natural Resources 16: 387-413. 
Tefera M. 2011. Wildlife in Ethiopia: endemic large mammals. World Journal of Zoology 6: 108-116.

Teferra F, Beyene F. 2014. Indigenous claims and conflicts in managing the Abijata-Shalla Lakes National Park, Ethiopia. International Journal of Biodiversity Science, Ecosystem Services \& Management 10: 216-227.

Teshome Z, Girmay, T. 2017. Human-wildlife conflict: challenge and management in Ethiopia: a review. International Journal of Emerging Trends in Science and Technology 4: 5004-5009.

Tessema M, Zelalem A, Lilieholm J, Leader-Williams N. 2010. Community attitudes towards wildlife conservation in Ethiopia. Society \& Natural Resources 23: 48-506.

Tilahun B, Abie K, Feyisa A, Amare A. 2017. Attitude and perceptions of local communities towards the conservation value of Gibe Sheleko National Park, southwestern Ethiopia, Agricultural and Resource Economics 3: 65-77.

UNDP (United Nations Development Programme). 2012. Guassa-Menz community conservation area, Ethiopia. Equator initiative case study series. New York. Pp. 10.

West P, Igoe J, Brockington D. 2006. Parks and peoples: the social impact of protected areas. Annual Review of Anthropology 35: 251-277. 